\title{
PATERNAL OCCUPATIONAL EXPOSURES AND THE RISK OF CONGENITAL MALFORMATIONS - A CASE-CONTROL STUDY
}

\author{
MOHAMED EL-HELALY ${ }^{1}$, KAMAL ABDEL-ELAH ${ }^{2}$, AYMAN HAUSSEIN ${ }^{3}$, and HEND SHALABY ${ }^{4}$
}

${ }^{1}$ The Mansoura University, Mansoura, Egypt

Department of Public Health and Preventive Medicine, Faculty of Medicine

${ }^{2}$ The Mansoura University, Mansoura, Egypt

Department of Pediatric Surgery, Faculty of Medicine

${ }^{3}$ The Mansoura University, Mansoura, Egypt

Department of Orthopedics; Faculty of Medicine

${ }^{4}$ The Mansoura University, Mansoura, Egypt

Department of Gynecology and Obstetrics, Faculty of Medicine

\begin{abstract}
Objectives: This study examined the association between certain paternal occupational exposures during the periconceptional period and the risk of congenital malformations. Materials and Methods: A case-control study was carried out from December 2009 to April 2010; on 242 congenital malformation cases and 270 controls. Paternal occupational exposure to certain workplace hazards was assessed by a detailed questionnaire to evaluate the occupational exposure for both fathers and mothers including pesticides, solvents, welding fumes, lead, working with video display terminals (VDTs) and computer monitors. In addition, the questionnaire assessed the presence of other risk factors such as consanguinity, smoking and history of any maternal diseases during the pregnancy with the child. Results: The results revealed that the odds of having a child with congenital malformation was higher $(\mathrm{P}<0.01)$ if the father was occupationally exposed to pesticides (OR: 3.42, 95\% CI: 1.97-5.92), solvents (OR: 5.63, 95\% CI: 2.77-11.42), or welding fumes (OR: 2.98, 0.99-8.54) during the periconceptional period. However, consanguinity (OR: 1.91, 95\% CI: 1.25-2.92) was a risk factor of developing congenital malformations among offspring. Conclusion: Control of workplace exposures and adherence to threshold limit values of those hazards should be adopted to minimize the risk of developing congenital malformations among offspring.
\end{abstract}

Key words:

Paternal, Occupational exposure, Congenital malformation, Risk

\section{INTRODUCTION}

Congenital malformations or birth defects are common among all races, cultures, and socioeconomic strata. Birth defects can be isolated abnormalities or a part of a syndrome and continue to be an important cause of neonatal and infant morbidity and mortality. Based on a World Health Organization (WHO) report, about 3 million fetuses and infants are born each year with major congenital malformations; congenital malformations accounted for an estimated 495,000 deaths worldwide in 1997 [1]. Several

Received: February 7, 2011. Accepted: March 14, 2011.

Address reprint request to M. El-Helaly, Public Health and Preventive Medicine Department, Faculty of Medicine, Mansoura University, Mansoura, Egypt PO 35516 (e-mail: mhelaly72@gmail.com). 
large population-based studies place the incidence of major malformations at about 2-3\% of all live births [2-6]. Occupational and environmental agents are the suspected causes responsible for about $60 \%$ of birth defects with unknown etiology [7]. The existence of hazards in the workplace environment has raised concerns about the potential of these substances for adverse reproductive effects. Historically, studies assessing the role of occupational exposures as etiological agents for birth defects focused on maternal exposures during pregnancy [8]. The role of paternal exposure received less attention despite animal evidence showing that exposures of males to toxic agents may result in congenital malformations in the offspring [9-12]. With increasing concern about male reproductive function raised in the past decade, epidemiological studies are being published taking into account the role of paternal exposures by evaluating paternal occupations and risk of birth defects [8]. It is suspected that environmental and occupational contaminants induce mutations resulting in increased risk for such defects in subsequent generations of the persons exposed [13]. Paternal occupational exposures are likely to affect congenital malformations through the spermatogenesis cycle. However, development and functional maturation extend beyond organogenesis and even beyond the moment of birth, affording a much wider time span of opportunities for harmful effects than it was traditionally thought [8]. Thus, the objective of the present study is to investigate the association between the occurrence of birth defects and the paternal workplace exposures.

\section{MATERIALS AND METHODS}

A case-control study was conducted in Egypt between 2008 and 2009 at the Pediatric Hospital, Mansoura University, Mansoura, Egypt. It was approved by Mansoura University ethics committee and all participants filled a written formal consent to participate in the research with description of its objectives. A case patient was defined as a child diagnosed with any type of congenital malformations classified by the International Classification of Diseases, tenth revision (ICD-10) [14].

All congenital malformation cases were recruited during their initial hospitalization for surgery in the pediatric surgery department in the period from December 2009 to April 2010. The exclusion criteria included any case who had one or both parents dead or not present at the time of the interview, cases whose mothers had history of disease or drug intake during the pregnancy of the cases in question, any cases whose father, mother or both had history of $\mathrm{DM}$, renal or liver diseases and any case with family history of genetic diseases or congenital malformations. The total number of the recruited cases was 327 , however, parents of 31 cases refused to participate, mothers of 28 cases had history of infections and drug intake during the pregnancy of the cases, 19 cases had a family history of congenital malformations, and 7 cases had fathers with a history of DM. Thus, the final sample size was 242 cases and the participation rate was $90.52 \%$ (296 cases agreed to participate from the total of 327 cases).

Two hundred and seventy control children were selected by a simple random sampling technique, at the same hospital, out of children with no birth defect, cancer, or genetic disease, but hospitalized for treatment of some other disorder, mostly infections (respiratory or urinary system), or the need for minor surgery (nevus, fractures). The controls matched the cases as for the age and demographic characteristics.

\section{Assessment of occupational and environmental exposure}

The fathers and mothers of the cases, as well as the controls, were interviewed at the hospital premises by a trained physician and completed a questionnaire including questions about their personal history, past history of diseases, family history of congenital malformations, socioeconomic features, smoking, residence, and three-month periconceptional [15] occupational exposures to pesticides, solvents (including: glues, adhesives, polishes, thinners or turpentine), 
welding fumes, lead, working with video display terminals (VDTs) and computer monitors and other exposures. Parental Occupations were classified according to the International Standard Classifications of Occupations (ISCO-08) [16]. In addition, the questionnaire included questions about the history of consanguinity and mother's medical and obstetrical history, exposure to X-ray and surgery during pregnancy, as well as infectious diseases and drug intake.

\section{Statistical analysis}

Baseline demographic information for the cases and the controls was compared. Next, bivariate analyses were performed to determine the association between congenital malformations and exposure factors based on a priori hypotheses. Bivariate analyses were performed using student-t test for continuous variables and the Pearson Chi-Square and Fisher's exact tests for categorical and dichotomous variables. Next, a multivariable logistic regression model was employed using forward Wald strategy. Candidates' variables had a bivariate association with congenital malformations of $\mathrm{P}<0.05$. The odds ratio (OR) and 95\% confidence intervals (CI) were calculated for case-control associations with factors suspected to be associated to congenital malformations, with adjustment of the confounders (including: father's and mother's age at the child birth, maternal occupations, child's age and sex, paternal and maternal education, family residence and income, paternal smoking and consanguinity). Statistical analysis was performed using SPSS, version 16.0, on a personal computer. A two-tailed $\mathrm{P}$ value was considered statistically significant if equal to or less than 0.05 , and highly statistically significant if less than 0.01 .

\section{RESULTS}

Among the total cases of congenital malformations, gastrointestinal system malformations were the most frequent $(50.8 \%)$, followed by genito-urinary system, musculoskeletal system and central nervous system malformations (26.4\%, $11.2 \%$ and $7.9 \%$; respectively). However, those connected with the respiratory and cardiovascular systems constituted the least frequent malformations ( $2.1 \%$ and $1.75 \%$; respectively). In addition, $8.7 \%$ of the total malformations were multiple (Table 1).

Table 1. Pattern of congenital malformations among the cases

\begin{tabular}{lrr}
\hline \multirow{2}{*}{ Type of congenital malformations } & \multicolumn{2}{c}{ Cases } \\
\cline { 2 - 3 }$(\mathrm{N}=$ & $242)$ \\
\hline Central nervous system & 19 & 7.9 \\
Anencephaly Q00.0 & 5 & 2.1 \\
Encephalocele Q01.0 & 3 & 1.2 \\
Congenital hydrocephalus Q03.0 & 9 & 3.7 \\
Spina bifida Q05.0 & 2 & 0.8 \\
Cardiovascular system & 4 & 1.7 \\
Congenital aneurism of abdominal & 3 & 1.2 \\
aorta Q25.4 & & \\
Congenital renal artery stenosis Q27.1 & 1 & 0.4 \\
Respiratory system & 5 & 2.1 \\
Congenital absence of nose Q30.1 & 1 & 0.4 \\
Laryngocele Q31.3 & 3 & 1.2 \\
Congenital stenosis of trachea Q32.1 & 1 & 0.4 \\
Gastrointestinal system & 123 & 50.8 \\
Cleft lip and/or palate Q35- Q37 & 29 & 12.0 \\
Congenital trachea-esophageal & 8 & 3.3 \\
fistula Q39.2 & & \\
Congenital hypertrophic pyloric & 15 & 6.2 \\
stenosis Q40.0 & & \\
Congenital hiatus hernia Q40.1 & 3 & 1.2 \\
Congenital stenosis of duodenum Q41.0 & 4 & 1.7 \\
Congenital stenosis of rectum Q42.1 & 5 & 2.1 \\
Imperforate anus Q42.3 & 13 & 5.4 \\
Hirschsprung's disease Q43.1 & 28 & 11.8 \\
Congenital dilatation of colon Q43.2 & 5 & 2.1 \\
Congenital fistula of rectum & 13 & 5.4 \\
and anus Q43.6 & & \\
\hline & & \\
\hline
\end{tabular}


Table 1. Pattern of congenital malformations among the cases - cont.

\begin{tabular}{lrr}
\hline \multirow{2}{*}{ Type of congenital malformations } & \multicolumn{2}{c}{ Cases } \\
\cline { 2 - 3 }$(\mathrm{N}=242)$ \\
\cline { 2 - 3 } Genito-urinary system & $\mathrm{n}$ & $\%$ \\
\hline Developmental ovarian cyst Q50.1 & 1 & 26.4 \\
Undescended testicle Q53 & 17 & 7.4 \\
Hypospadias Q54 & 33 & 13.5 \\
Hermaphroditism Q56 & 4 & 1.7 \\
Renal agenesis Q60 & 2 & 0.8 \\
Polycystic kidney Q60.1 & 1 & 0.4 \\
Congenital hydronephrosis Q62 & 1 & 0.4 \\
Ectopiavesicae Q64.1 & 5 & 2.1 \\
Musculoskeletal system & 27 & 11.2 \\
Congenital dislocation of hip Q65.1 & 9 & 3.7 \\
Talipesequinovarus Q66 & 11 & 4.6 \\
Syndactyly Q70 & 7 & 2.8 \\
Multiple & 21 & 8.7 \\
\hline
\end{tabular}

The cases did not differ significantly from the controls regarding the paternal and maternal age at child birth and child's age at the interview, however the child's sex distribution varied significantly between both groups. Moreover, there was no statistically significant difference between the cases and the controls concerning the paternal and maternal level of education, family residence, family income and smoking. However, consanguinity was more frequent among the cases in comparison to the controls $(\mathrm{P}<0.01)$ (Table 2). As for paternal occupations, craftsmen and related trades workers, as well as skilled agricultural and fishery workers groups were the most frequent working groups among the cases (26.0\% and $17.8 \%$, respectively). They also were significantly more prevalent among the cases in comparison to the controls (17.7 and 8.9\%, respectively). However, professionals and clerks were more prevalent among the controls compared to the cases with statistically significant difference. In scope of maternal occupations, no statistically significant differences were observed between the cases and the controls, and most of the mothers of the cases and the controls were non-employed $(85.1 \%$ and $84.9 \%$, respectively) (Table 3 ).

Paternal workplace exposures to pesticides (OR:3.4, 95\% CI: 1.9-5.9), solvents (OR: 5.6, 95\% CI: 2.711.4), and welding fumes (OR: 2.9, 95\% CI: 0.9-8.5) were significantly associated with increased risk of congenital malformations among the offspring. Lead (OR: 2.9, 95\% CI: 0.9-8.5) was insignificantly associated with increased risk of congenital malformations. Paternal exposure to VDT and computers was not associated with congenital malformation. Apart from that, consanguinity (OR: 1.9, 95\% CI: 1.2-2.9) was a risk factor of developing congenital malformations among the offspring (Table 4).

Table 2. Basic characteristics of the cases of congenital malformations and the controls

\begin{tabular}{|c|c|c|c|c|c|c|}
\hline \multirow[t]{2}{*}{ Characteristic } & \multicolumn{2}{|c|}{$\begin{array}{c}\text { Cases } \\
(\mathrm{N}=242)\end{array}$} & \multicolumn{2}{|c|}{$\begin{array}{c}\text { Controls } \\
(\mathrm{N}=270)\end{array}$} & \multirow[t]{2}{*}{ Test } & \multirow[t]{2}{*}{$\mathrm{P}$} \\
\hline & \multicolumn{2}{|c|}{ mean \pm SD } & \multicolumn{2}{|c|}{ mean \pm SD } & & \\
\hline Paternal age at child birth (years) & \multicolumn{2}{|c|}{$34.4(7.2)$} & \multicolumn{2}{|c|}{$34.24(6.9)$} & 0.2 & $>0.05$ \\
\hline Maternal age at child birth (years) & \multicolumn{2}{|c|}{$27.8(6.1)$} & \multicolumn{2}{|c|}{$28.1(6.0)$} & 0.5 & $>0.05$ \\
\hline \multirow[t]{2}{*}{ Child's age at the interview(years) } & \multicolumn{2}{|c|}{$3.1(2.9)$} & \multicolumn{2}{|c|}{$2.9(2.8)$} & 0.7 & $>0.05$ \\
\hline & $\mathrm{n}$ & $\%$ & $\mathrm{n}$ & $\%$ & & \\
\hline \multicolumn{5}{|l|}{ Child's sex } & 2.8 & $<0.05$ \\
\hline male & 162 & 66.9 & 199 & 73.7 & & \\
\hline female & 80 & 33.1 & 71 & 26.3 & & \\
\hline
\end{tabular}


Table 2. Basic characteristics of the cases of congenital malformations and the controls - cont.

\begin{tabular}{|c|c|c|c|c|c|c|}
\hline \multirow[t]{2}{*}{ Characteristic } & \multicolumn{2}{|c|}{$\begin{array}{c}\text { Cases } \\
(\mathrm{N}=242)\end{array}$} & \multicolumn{2}{|c|}{$\begin{array}{c}\text { Controls } \\
(\mathrm{N}=270)\end{array}$} & \multirow[t]{2}{*}{ Test } & \multirow[t]{2}{*}{$\mathrm{P}$} \\
\hline & & & & & & \\
\hline illiterate & 35 & 14.5 & 38 & 14.1 & & \\
\hline read and write / primary school & 34 & 14.0 & 40 & 14.8 & & \\
\hline preparatory / secondary school & 94 & 38.8 & 104 & 38.5 & & \\
\hline university graduated or higher & 79 & 32.6 & 88 & 32.6 & & \\
\hline Maternal Education & & & & & 4.5 & $>0.05$ \\
\hline illiterate & 36 & 14.9 & 29 & 10.7 & & \\
\hline read and write / primary school & 52 & 21.5 & 47 & 17.4 & & \\
\hline preparatory / secondary school & 106 & 43.8 & 127 & 47.0 & & \\
\hline university graduated or higher & 48 & 19.8 & 67 & 24.8 & & \\
\hline Family residence & & & & & 0.4 & $>0.05$ \\
\hline rural & 177 & 73.1 & 204 & 75.6 & & \\
\hline urban & 65 & 26.9 & 66 & 24.4 & & \\
\hline Family income & & & & & 1.4 & $>0.05$ \\
\hline enough & 102 & 42.1 & 129 & 47.8 & & \\
\hline not enough & 140 & 57.9 & 141 & 52.2 & & \\
\hline Consanguinity & 80 & 33.1 & 56 & 20.7 & 9.9 & $<0.01$ \\
\hline Paternal smoking & & & & & 2.7 & $>0.05$ \\
\hline non-smoker & 99 & 40.9 & 130 & 48.1 & & \\
\hline current smoker & 143 & 59.1 & 140 & 51.9 & & \\
\hline
\end{tabular}

Table 3. Paternal and maternal occupations among the cases of congenital malformations and the controls

\begin{tabular}{|c|c|c|c|c|c|c|}
\hline \multirow{2}{*}{ Occupations } & \multicolumn{2}{|c|}{$\begin{array}{c}\text { Cases } \\
(\mathrm{N}=242)\end{array}$} & \multicolumn{2}{|c|}{$\begin{array}{c}\text { Controls } \\
(\mathrm{N}=270)\end{array}$} & \multirow{2}{*}{ Test } & \multirow{2}{*}{$\mathrm{P}$} \\
\hline & $\mathrm{n}$ & $\%$ & $\mathrm{n}$ & $\%$ & & \\
\hline \multicolumn{7}{|l|}{ Paternal Occupations } \\
\hline professionals & 40 & 16.5 & 65 & 24.1 & 4.50 & $<0.05$ \\
\hline technicians and associate professionals & 30 & 12.4 & 36 & 13.3 & 0.10 & $>0.05$ \\
\hline clerks & 26 & 10.7 & 52 & 19.3 & 7.20 & $<0.01$ \\
\hline service workers and shop and market sales workers & 9 & 3.7 & 14 & 5.2 & 0.60 & $>0.05$ \\
\hline skilled agricultural and fishery workers & 43 & 17.8 & 24 & 8.9 & 8.90 & $<0.01$ \\
\hline craftsmen and related trades workers & 63 & 26.0 & 48 & 17.7 & 5.10 & $<0.05$ \\
\hline plant and machine operators and assemblers & 25 & 10.3 & 19 & 7.0 & 1.80 & $>0.05$ \\
\hline elementary occupations & 3 & 1.2 & 11 & 4.1 & 3.90 & $>0.05$ \\
\hline armed forces & 2 & 0.8 & 3 & 1.1 & 0.10 & $>0.05$ \\
\hline
\end{tabular}


Table 3. Paternal and maternal occupations among the cases of congenital malformations and the controls - cont.

\begin{tabular}{|c|c|c|c|c|c|c|}
\hline \multirow{2}{*}{ Occupations } & \multicolumn{2}{|c|}{$\begin{array}{c}\text { Cases } \\
(\mathrm{N}=242)\end{array}$} & \multicolumn{2}{|c|}{$\begin{array}{l}\text { Controls } \\
(\mathrm{N}=270)\end{array}$} & \multirow{2}{*}{ Test } & \multirow[t]{2}{*}{$\mathrm{P}$} \\
\hline & $\mathrm{n}$ & $\%$ & $\mathrm{n}$ & $\%$ & & \\
\hline \multicolumn{7}{|l|}{ Maternal Occupations } \\
\hline non-employed & 206 & 85.1 & 228 & 84.4 & & \\
\hline professionals & 26 & 10.7 & 21 & 7.8 & & \\
\hline clerks & 1 & 0.4 & 6 & 2.2 & 6.84 & $>0.05$ \\
\hline service workers and shop and market sales workers & 1 & 0.4 & 0 & 0.0 & & \\
\hline skilled agricultural and fishery workers & 8 & 3.3 & 15 & 5.6 & & \\
\hline
\end{tabular}

Table 4. Odds ratios (OR) of the risk factors associated with the congenital malformations among the study population

\begin{tabular}{|c|c|c|c|c|}
\hline \multirow{2}{*}{$\begin{array}{c}\text { Risk factors }{ }^{\mathrm{a}} \\
\text { Workplace Exposures }\end{array}$} & $\begin{array}{c}\text { Cases } \\
(\mathrm{N}=242) \\
\end{array}$ & $\begin{array}{c}\text { Controls } \\
(\mathrm{N}=270)\end{array}$ & \multirow[t]{2}{*}{ OR $(95 \% \mathrm{CI})$} & \multirow[t]{2}{*}{$\mathrm{P}$} \\
\hline & $\mathrm{n}(\%)$ & $\mathrm{n}(\%)$ & & \\
\hline Pesticides & $49(20.2)$ & $23(8.5)$ & $3.4(1.9-5.9)$ & $<0.01$ \\
\hline Solvents & 45 (18.6) & $11(4.1)$ & $5.6(2.7-11.4)$ & $<0.01$ \\
\hline Welding fumes & $36(14.9)$ & $9(3.3)$ & $2.9(1.2-7.3)$ & $<0.05$ \\
\hline Lead & $25(10.3)$ & $6(2.2)$ & $2.9(0.9-8.5)$ & $>0.05$ \\
\hline VDT and computers & $25(10.3)$ & $24(8.9)$ & $1.2(0.7-2.1)$ & $>0.05$ \\
\hline Consanguinity & $80(33.1)$ & $56(20.7)$ & $1.9(1.2-2.9)$ & $<0.01$ \\
\hline
\end{tabular}

${ }^{a}$ Multiple exposures constituted 9\% of the total reported exposures among the cases and 5.5\% among the controls. Moreover, $25.6 \%$ of the cases and $73.0 \%$ of the controls reported no exposures to the studied exposure factors.

\section{DISCUSSION}

This study examined the association between certain paternal workplace exposures and the increased probability of having a child with congenital malformations. We used standard international classifications both for the types of congenital malformations (ICD-10) and for parental occupations (ISCO-08). We assessed paternal workplace exposure during the periconceptional period as, depending on biological consideration and experimental evidence, most studies concentrated on the exposure period of 3 or 6 months before conception and the first trimester of pregnancy [17-19]. The controls matched the congenital malformation cases concerning the basic characteristics except the child's sex distribution. The results were adjusted for potential confounding factors using logistic regression. However, consanguinity (OR: 1.9, 95\% CI: 1.2-2.9) was a risk factor of developing congenital malformations among the offspring.

As for the paternal occupations, the research results demonstrated that the fathers of the congenitally malformed children were significantly more likely to be craftsmen and employees of related trades, as well as skilled agricultural and fishery workers. However, the fathers of the congenitally malformed children were significantly less likely to be professionals or clerks. There was no significant association between maternal occupations and developing congenital malformations in the offspring. This is in agreement with other studies stating that fathers employed as 
janitors, woodworkers, firemen, electrical workers, printers, and painters were reported to be at increased risk of having a child with a birth defect [20-21]. Exposures related to these occupations include solvents, wood and wood products, metals, and pesticides [22].

Using logistic regression, it was shown that the fathers occupationally exposed to pesticides (OR: 3.4, 95\% CI: 1.9-5.9), solvents (OR: 5.6, 95\% CI: 2.7-11.4), and welding fumes (OR: 2.98, 95\% CI: 0.99-8.54) were significantly more likely to have congenitally malformed children.

The study results revealed that the fathers occupationally exposed to pesticides (OR: 3.4, 95\% CI: 1.9-5.9) were significantly more likely to have children with congenital malformations. This supports other studies that reported an association between agricultural work and/or exposure to pesticides experienced by the father, or the mother, or both; and different adverse reproductive effects such as congenital malformations in general [23-25], cleft lip and palate [26-27], musculoskeletal defects [28], limb reduction defects [29-30], and central nervous system defects [31-33]. Environmental or occupational exposure to pesticides may cause alterations in the male gametes prior to conception, as well as embryonic damage or feto-placental complex. The latter may be due to the presence of pesticides in the seminal fluid of the father resulting from liberation of the toxins accumulated in the body [34].

On the other hand, negative findings were reported by some studies on the relation between paternal agricultural work, exposures to pesticides, and selected birth defects such as nervous system anomalies, cardiovascular anomalies, oral clefts, hypospadias, epispadias, musculoskeletal anomalies, and non-specific anomalies [35-36]

In the present study, paternal exposure to solvents was a significant risk factor of congenital malformations (OR: 5.6, 95\% CI: 2.7-11.4). This is in accordance with Logman et al. (2005) [37], who carried out a meta-analysis that showed an association between exposure to solvents and major malformations. Moreover, Hooivel et al. [38], concluded that their research showed a positive association between paternal occupational exposure to organic solvents and congenital malformations in the offspring. However, a small number of cases, especially when examining different exposure levels, as well as the self-reported nature of exposure and outcome variables, may hamper interpretation of the results.

Our study showed that paternal exposure to welding fumes was significantly associated with congenital malformations (OR: 2.9, 95\% CI: 0.9-8.5). This is in line with the results obtained by Quansah and Jaakkola [39], who carried out a study to assess whether paternal exposure (prior to conception) and maternal exposure (during pregnancy) to welding fumes and metal dusts or fumes independently and jointly increases the risk of adverse pregnancy outcomes. They found suggestive evidence that paternal exposure to welding fumes may increase the risk of adverse pregnancy outcomes.

Lead has for long been known to affect multiple organs and can affect the reproduction capacity in males and females, as well as that of the offspring, since lead can have a direct toxic effect on sperm, or an indirect effect through endocrine dysfunction [40-42]. However, the present study reported that lead was not a significant risk factor of congenital malformations. Irgens et al., in a population study investigated the reproductive outcome in the offspring of parents who were occupationally exposed to lead in Norway. In that research, the offspring of fathers exposed to lead had no increased risks of any of the analyzed birth defects, although mothers exposed to lead had a significantly increased risk of neural tube defects [43].

The present study has many advantages; the sample size was considerably good and the participation rate was high. Furthermore, adjustment of the confounders was carried out, but even after it, consanguinity still remained a risk factor of congenital malformations. However, this study assessed the association between congenital 
malformations and exposure to pesticides and solvents in general, but not to their specific chemical types. In addition, we did not relate the risk to specific biological marker, as it was difficult to execute at the time of conducting the study due to the wide array of chemicals that the workers were exposed to. Moreover, the case-control design inherently cannot evaluate causality. Further studies are needed to examine the risk of different types of congenital malformations and the paternal occupational exposures through biological monitoring and specific assessment of exposures.

In conclusion, paternal workplace exposures to pesticides, solvents, and welding fumes may be risk factors of developing congenital malformations among the offspring. Thus, workplace exposure control, adherence to threshold limit values, proper use of personal protective equipment and respirators, as well as health education about safety and hazards of occupational exposure to chemicals should be adopted to minimize the risk of developing congenital malformations among the offspring of the workers.

\section{REFERENCES}

1. Rosano A, Botto LD, Botting B, Mastroiacovo P. Infant mortality and congenital anomalies from 1950 to 1994: an international perspective. J Epidemiol Community Health 2000;54(9): 660-6.

2. Dastgiri S, Stone DH, Le-Ha C, Gilmour WH. Prevalence and secular trend of congenital anomalies in Glasgow, UK. Arch Dis Child 2002;86(4):257-63.

3. De Vigan C, Khoshnood B, Lhomme A, Vodovar V, Goujard J, Goffinet F. Prevalence and prenatal diagnosis of congenital malformations in the Parisian population: twenty years of surveillance by the Paris Registry of congenital malformations. J Gynecol Obstet Biol Reprod 2005;34:8-16.

4. Richmond S, Atkins J. A population-based study of the prenatal diagnosis of congenital malformation over 16 years. BJOG 2005;112(10):1349-57.
5. Tan KH, Tan TY, Tan J, Tan I, Chew SK, Yeo GS. Birth defects in Singapore: 1994-2000. Singapore Med J 2005;46(10): $545-52$.

6. Ali A, Zahad S, Masoumeh A, Azar A. Congenital malformations among live births at Arvand Hospital, Ahwaz, Iran A prospective study. Pak J Med Sci 2008;24(1):33-7.

7. Varela MM, Nohr EA, Llopis-González A, Andersen AM, Olsen J. Socio-occupational status and congenital anomalies. Eur J Public Health 2009;19(2):161-7.

8. Chia SE, Shi LM. Review of recent epidemiological studies on paternal occupations and birth defects. Occup Environ Med 2002;59:149-55.

9. Fernie K, Bortolotti G, Smits J. Reproductive abnormalities, teratogenicity, and developmental problems in American kestrels (Falco sparverius) exposed to polychlorinated biphenyls. J Toxicol Environ Health A 2003;66(22):2089-103.

10. Cordier S. Evidence for a role of paternal exposures in developmental toxicity. Basic Clin Pharmacol Toxicol 2008;102(2):176-81.

11. Hansen DA. Paternal environmental exposures and gene expression during spermatogenesis: research review to research framework. Birth Defects Res C Embryo Today 2008;84(2):155-63.

12. Tamminga J, Koturbash I, Baker M, Kutanzi K, Kathiria P, Pogribny IP, et al. Paternal cranial irradiation induces distant bystander DNA damage in the germline and leads to epigenetic alterations in the offspring. Cell Cycle 2008;7(9):1238-45.

13. Narod SA, Douglas GR, Nestmann ER. Human mutagens: Evidence from paternal exposure? Environ Mol Mutagen 2006;11(3):401-15.

14. World Health Organization (WHO). International classification of diseases, tenth revision (ICD-10). Geneva: World Health Organization; 1992.

15. Aguilar-Garduño C, Lacasaña M, Blanco-Muñoz J, BorjaAburto VH, García AM. Parental occupational exposure to organic solvents and anencephaly in Mexico. Occup Environ Med 2010;67:32-7.

16. International Labor Office. International standard classification of occupations - 08. Geneva: International Labor Office; 2007. 
17. Krapels IP, Zielhuis GA, Vroom F, de Jong-van den Berg LT, Kuijpers-Jagtman AM, van der Molen AB, et al. Periconceptional health and lifestyle factors of both parents affect the risk of live-born children with orofacial clefts. Birth Defects Res A Clin Mol Teratol 2006;76(8):613-20.

18. Yang Q, Wen SW, Leader A, Chen XK, Lipson J, Walker M. Paternal age and birth defects: how strong is the association? Hum Reprod 2007; 22(3):696-701.

19. Sung TI, Wang JD, Chen PC. Increased risks of infant mortality and of deaths due to congenital malformation in the offspring of male electronics workers. Birth Defects Res A Clin Mol Teratol 2009;85(2):119-24.

20. Chia SE, Shi LM, Chan OY. A population-based study on the association between parental occupations and some common birth defects in Singapore (1994-1998). J Occup Environ Med 2004;46(9):916-23.

21. Lin CC, Wang JD, Hsieh GY, Chang YY, Chen PC. Increased risk of death with congenital anomalies in the offspring of male semiconductor workers. Int J Occup Environ Health 2008;14(2):112-6.

22. Aguilar-Garduño C, Lacasaña M, Blanco-Muñoz J, Borja-Aburto VH, García AM. Parental occupational exposure to organic solvents and anencephaly in Mexico. Occup Environ Med 2010;67(1):32-7.

23. Heeren GA, Tyler J, Mandeya A. Agricultural chemical exposures and birth defects in the Eastern Cape Province, South Africa: A case-control study. Environ Health 2003;4;2(1):11.

24. Zhu JL, Hjollund NH, Andersen AM. Occupational exposure to pesticides and pregnancy outcomes in gardeners and farmers: a study within the Danish National Birth Cohort. J Occup Environ Med 2006;48(4):347-52.

25. Rocheleau CM, Romitti PA, Dennis LK. Pesticides and hypospadias: a meta-analysis. J Pediatr Urol 2009;5(1):17-24.

26. Romitti PA, Herring AM, Dennis LK, Wong-Gibbons DL. Meta-analysis: pesticides and orofacial clefts. Cleft Palate Craniofac J 2007;44(4):358-65.

27. González BS, López ML, Rico MA, Garduño F. Oral clefts: a retrospective study of prevalence and predisposal factors in the State of Mexico. J Oral Sci 2008;50(2):123-9.
28. Hanke W, Jurewicz J. The risk of adverse reproductive and developmental disorders due to occupational pesticide exposure: an overview of current epidemiological evidence. Int J Occup Med Environ Health 2004;17(2):223-43.

29. Engel LS, O'Meara ES, Schwartz SM. Maternal occupation in agriculture and risk of limb defects in Washington State, 19801993. Scand J Work Environ Health 2000;26(3):193-8.

30. Irgens A, Krüger K, Skorve AH. Birth defects and paternal occupational exposure. Hypotheses tested in a record linkage based dataset. Acta Obstet Gynecol Scand 2000;79(6): $465-70$.

31. Lacasaña M, Vázquez-Grameix H, Borja-Aburto VH, Blanco-Muñoz J, Romieu I, Aguilar-Garduño C, et al. Maternal and paternal occupational exposure to agricultural work and the risk of anencephaly. Occup Environ Med 2006;63(10):649-56.

32. Fear NT, Hey K, Vincent T, Murphy M. Paternal occupation and neural tube defects: a case-control study based on the Oxford Record Linkage Study register. Paediatr Perinat Epidemiol 2007;21(2):163-8.

33. Ngo AD, Taylor R, Roberts CL. Paternal exposure to Agent Orange and spina bifida: A meta-analysis. Eur J Epidemiol 2010;25(1):37-44.

34. Lacasaña M, Vázquez-Grameix H, Borja-Aburto VH, Blanco-Muñoz J, Romieu I, Aguilar-Garduño C, et al. Maternal and paternal occupational exposure to agricultural work and the risk of anencephaly. Occup Environ Med 2006;63(10): 649-56.

35. Lin S, Marshall EG, Davidson GK. Potential parental exposure to pesticides and limb reduction defects. Scand J Work Environ Health 1994;20:166-79.

36. Shaw GM, Velie EM, Katz EA, Morland KB, Schaffer DM, Nelson V. Maternal occupational and chemical hobby exposures as risk factors for neural tube defects. Epidemiology 1999;10:124-9.

37. Logman JF, de Vries LE, Hemels ME, Khattak S, Einarson TR. Paternal organic solvent exposure and adverse pregnancy outcomes: A meta-analysis. Am J Ind Med 2005;47: $37-44$. 
38. Hooiveld M, Haveman W, Roskes K, Bretveld R, Burstyn I, Roeleveld N. Adverse reproductive outcomes among male painters with occupational exposure to organic solvents. Occup Environ Med 2006;63;538-44.

39. Quansah R, Jaakkola JJ. Paternal and maternal exposure to welding fumes and metal dusts or fumes and adverse pregnancy outcomes. Int Arch Occup Environ Health 2009;82(4): 529-37.

40. Fatima P, Debnath BC, Hossain MM, Rahman D, Banu J, Begum SA, et al. Relationship of blood and semen lead level with semen parameter. Mymensingh Med J 2010;19(3): 405-14.
41. El-Helaly M, Awadalla N, Mansour M, El-Biomy Y. Workplace exposures and male infertility - A case-control study. Int J Occup Med Environ Health 2010;23(4):331-8.

42. Vinceti M, Rovesti S, Bergomi M, Calzolari E, Candela S, Campagna A, et al. Risk of birth defects in a population exposed to environmental lead pollution. Sci Total Environ 2001;278(1-3):23-30.

43. Irgens A, Krüger K, Skorve AH, Irgens LM. Reproductive outcome in offspring of parents occupationally exposed to lead in Norway. Am J Ind Med 1998;34:431-37.

This work is available in Open Access model and licensed under a Creative Commons Attribution-NonCommercial 3.0 Poland License - http://creativecommons.org/ licenses/by-nc/3.0/pl/deed.en. 